\title{
A geração de resíduos sólidos em um processo produtivo de uma indústria automobilística: uma contribuição para a redução
}

\section{Solid waste generation in the production process of an automobile industry: a contribution to its reduction}

\author{
Cíntia Madureira Orth ${ }^{1}$ \\ Nelma Baldin ${ }^{1}$ \\ Cladir Teresinha Zanotelli²
}

\begin{abstract}
Resumo: É sabido que a produção de resíduos industriais constitui uma das principais formas de degradação do meio ambiente. As indústrias têm empreendido um esforço crescente para tornarem seus processos produtivos menos agressivos, especialmente no que se refere à geração e gestão de resíduos sólidos. O objetivo desta pesquisa consistiu em estudar a geração de resíduos sólidos no processo produtivo de uma indústria automobilística, visando a apresentação de ações de redução. O estudo se deu por meio de observações in loco, registros fotográficos e cálculos da quantidade de resíduos sólidos gerados no processo de Moldagem e Acabamento em Plástico Reforçado com Fibra de Vidro. Constatou-se que a moldagem do tipo aberta, adotada pela fábrica, representa a principal fonte de geração de resíduos. Outra fonte refere-se ao desperdício de materiais, atribuído à falta de capacitação e de Educação Ambiental. Concluiu-se que a migração para um processo mais limpo e a adoção de um Programa de Educação Ambiental devem ser consideradas pela unidade fabril estudada.
\end{abstract}

Palavras-chave: Resíduos industriais. Produção Mais Limpa. Educação Ambiental. Indústria automobilística.

\begin{abstract}
The production of industrial waste is one of the main causes of environmental degradation. The industries have demonstrated an increasing effort to make their productive processes less harmful, especially regarding the generation and management of solid waste. The objective of this research was to study the solid waste generated in the manufacturing process of an automobile company in order to propose waste reduction action plan. The study was carried out based on observations in loco, photos, and calculations of the quantity of solid waste generated in the process of Molding and Finish of Fiberglass Reinforced Plastic parts. It was observed that the open mold process adopted by the factory represents the main source of waste generation. Another source of material waste lies in the lack of qualification and Environmental Education. It was concluded that the adoption of a cleaner production process and an Environmental Education Program should be considered by the company studied.
\end{abstract}

Keywords: Industrial Waste. Cleaner Production. Environmental Education. Automotive industry.

\section{Introdução}

Dentre os problemas ambientais que assolam a humanidade, a produção de resíduos industriais constitui uma das principais formas de degradação do meio ambiente. Não há dados precisos e atualizados da geração de resíduos industriais no Brasil, as estatísticas ainda são insuficientes. De acordo com o Instituto Brasileiro e Administração Municipal (2008), isso se deve, em parte, ao fato de que somente em 2002 o Conselho Nacional de Meio Ambiente (Conama) aprovou a Resolução n. 313, que dispõe sobre a obrigatoriedade do Inventário Nacional de
Resíduos Sólidos Industriais. Mas foram poucos os estados brasileiros que realizaram esse inventário.

Em se tratando especificamente da geração de resíduos industriais pelos segmentos plástico e automotivo, o Brasil é o sexto maior produtor de veículos do mundo e um dos maiores produtores de plásticos, o que torna o país um grande gerador de resíduos nesses segmentos (RIOS, 2003; SILVA, 2009). Considerando que a indústria automobilística é destaque no uso de materiais plásticos, que hoje compõem cerca de $15 \%$ dos veículos, podendo, em

\footnotetext{
${ }^{1}$ Programa de Mestrado em Saúde e Meio Ambiente, Universidade da Região de Joinville - UNIVILLE, Campus Universitário, s/n., Bom Retiro, CP 246, CEP 89201-972, Joinville, SC, Brasil, e-mail: cintia.orth@ hotmail.com; nelmabaldin@univille.br

${ }^{2}$ Universidade Federal do Mato Grosso - UFMT, Rua das Hortênsias, 1831, Centro, CEP 78550-000, Sinop, MT, Brasil,

e-mail: cladir.teresinha@hotmail.com
} 
2030, subir para $25 \%$ a 30\%, certamente haverá um aumento na geração de resíduos plásticos (FREITAS, 2013). Somente a indústria brasileira de compósitos de Plástico Reforçado com Fibra de Vidro (PRFV) gera cerca de 13 mil toneladas de resíduos por ano, das quais a maior parte tem como destino final os aterros industriais (LIMA, 2006). De acordo com o American Chemistry Council (2008), o uso expressivo de materiais plásticos pela indústria automobilística se deve, dentre outros motivos, ao fato de as peças plásticas chegarem a pesar até cerca de $50 \%$ menos que as similares em outros materiais. Tal característica torna os veículos mais leves, levando-os a consumir menos combustível.

Diante de toda essa problemática em torno da geração e gestão de resíduos, é chegado o momento de o setor industrial incorporar, com mais eficiência, a sustentabilidade em suas rotinas de trabalho, em especial no que diz respeito à adoção de processos produtivos menos agressivos. Para tanto, muitas são as políticas e ações ambientais disponíveis para as organizações empresariais dispostas a reduzir seus resíduos e/ou gerenciá-los corretamente, tais como: a Produção mais Limpa (P+L), a Política dos 3 Rs (Reduzir, Reutilizar, Reciclar), os Planos de Gerenciamento de Resíduos (PGR), os Programas de Educação Ambiental (PEA), os Sistemas de Gestão Ambiental (SGA) e tantas outras. Entretanto, ainda há uma grande resistência, por parte do empresariado, em implantar tais medidas. De acordo com o Conselho Empresarial Brasileiro para o Desenvolvimento Sustentável (2008), alguns empresários acreditam que a inserção da questão ambiental em suas empresas implicará em grandes investimentos, inclusive a adoção de novas tecnologias, mão de obra especializada e mudanças estruturais para a sua implementação quando, na realidade, aproximadamente $50 \%$ da poluição gerada pelas empresas pode ser evitada somente com a melhoria nas práticas de operação e com mudanças simples nos processos.

No que se refere a medidas eficientes, de fácil aplicabilidade, boa aceitação e que demandam poucos investimentos, destaca-se a implantação de Programas de Educação Ambiental, uma vez que a falta de sensibilidade ambiental, aliada à falta de preparo técnico dos operadores, ao manuseio e utilização inadequados de matérias-primas podem contribuir para a geração de resíduos (PINTO, 2002).

A Educação Ambiental é considerada o alicerce das Políticas Ambientais, ou seja, o sucesso de um SGA, de um PGR, da P+L e outros depende desse recurso. Entretanto, há empresários que demonstram uma certa indiferença com relação a essa ferramenta, embora estudos como os de, Barreto, Silva e Pádua (2008) e Coutinho et al. $(2009,2011)$ já tenham comprovado a sua eficiência no setor industrial. A Educação Ambiental, por exemplo, pode ser uma importante aliada no combate ao consumismo e ao desperdício de matéria-prima em processos produtivos. Ressalta-se que, para uma empresa, a redução do desperdício trará tanto benefícios ambientais quanto econômicos, uma vez que a empresa terá menos resíduos para gerenciar (FARIAS, 2003). Os funcionários precisam ser conscientizados dos efeitos ambientais de suas atividades, produtos e serviços (VILHENA; POLITI, 2005).

Em vista dessas questões, o objetivo que motivou o estudo que subsidia este artigo foi diagnosticar as principais fontes de geração de resíduos sólidos em um processo produtivo de uma indústria do setor automobilístico. Nesse sentido, visou-se a apresentação de ações que poderão contribuir para a redução da quantidade de resíduos provenientes do processo analisado.

\section{Metodologia}

Esta pesquisa representa um estudo transversal e observacional desenvolvido por meio de uma abordagem qualitativa e quantitativa. Foi aplicada em uma indústria que fabrica carrocerias para ônibus e tem sede no município de Joinville, SC, Brasil. A coleta dos dados ocorreu de janeiro a junho de 2009. O período analisado foi de maio de 2008 a abril de 2009.

\subsection{Caracterização do local de estudo}

A empresa estudada divide-se em três unidades: uma matriz e duas unidades de plásticos, uma localizada em Joinville, SC, e outra em Rio Negrinho, SC. A pesquisa foi feita somente na unidade de plásticos de Joinville. O processo analisado foi o de Moldagem e Acabamento em PRFV que, na referida unidade, abrange duas linhas de produção: tetos, produzidos em quatro modelos (Rodoviário, Urbano, Micro-ônibus e Panorâmico Dobledeck) e entrejanelas (modelo único). O processo divide-se em duas grandes etapas: Moldagem e Acabamento. A Figura 1 apresenta, para melhor compreensão, um fluxograma do processo. Mais detalhes são descritos a seguir.

A Moldagem das peças em PRFV inicia-se com a preparação dos moldes (limpador, selador e desmoldantes). Nos tetos, a parte final (não laminada) do molde é protegida com um plástico transparente. Em seguida, gel coat e catalisador são aplicados, simultaneamente, sobre a região a ser laminada com o uso de uma gelcoteadeira. Alguns minutos depois dá-se início à laminação, antes da qual todas as regiões (pisos e paredes) sujeitas à impregnação com aparas são protegidas com papelão ondulado.

A laminação dos tetos inicia-se com a aplicação manual do fio moído (fibra de vidro moída). Em seguida, fio roving picado, resina e catalisador são atirados, simultaneamente, por uma pistola picadora 


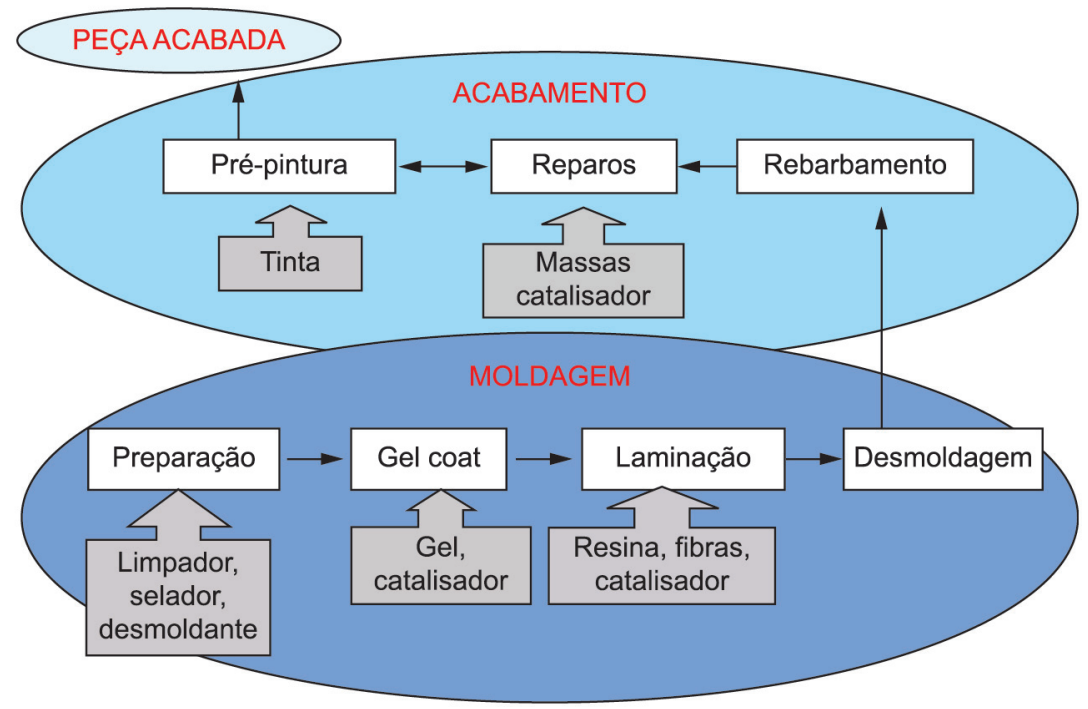

Figura 1. Fluxograma do processo de Moldagem e Acabamento em PRFV.

contra a cavidade do molde com o uso de uma laminadora semiautomática. O tecido e a manta de fibra de vidro são aplicados manualmente. Depois de aplicadas, as fibras são assentadas nos contornos do molde (roletes e pincéis). Terminada a laminação, as rebarbas nas duas laterais maiores dos tetos (quatro laterais ao todo) são removidas. Após a cura, ocorre a desmoldagem. Já na laminação das entrejanelas, a aplicação do fio roving inteiro e do fio moído é totalmente manual. Em seguida, essas fibras são umedecidas com resina e catalisador atirados, simultaneamente, por uma pistola. Posteriormente, aplica-se a manta e o tecido de fibra, que também são umedecidos com resina e catalisador. Faz-se o assentamento das fibras e, imediatamente após a laminação, todas as rebarbas (quatro laterais e vários vãos) são removidas. Após a cura, as entrejanelas são desmoldadas.

Após desmoldados, tetos e entrejanelas seguem para o Acabamento. Nessa etapa, as rebarbas das duas laterais menores dos tetos são removidas e todos os pontos de corte são lixados. Nas entrejanelas ocorre somente o lixamento, uma vez que todas as rebarbas foram removidas antes da desmoldagem. Após o rebarbamento, as peças seguem para um processo de reparação de possíveis imperfeições. Finalmente, são inteiramente lixadas e conduzidas para a pintura.

\subsection{Coleta de dados e procedimentos metodológicos}

O estudo das fontes de geração de resíduos deu-se por meio de observações in loco e registros fotográficos, sempre sob a orientação dos supervisores de produção do setor. Nessa etapa, além do detalhamento do processo, buscou-se identificar toda a matéria-prima usada, a sua forma de uso e/ou o processo gerador de resíduos, além dos resíduos gerados em cada uma das etapas do processo. As observações in loco permitiram, ainda, o estudo do comportamento dos funcionários quanto ao uso racional de matéria-prima e outros materiais.

Já a quantificação dos resíduos ocorreu por meio de consultas aos arquivos da empresa, medições e estimativas. Para o cálculo da quantidade de aparas de PRFV geradas mensalmente pela unidade, primeiramente levantaram-se dados da produção mensal no período estudado, discriminando-se a quantidade de peças moldadas (QPM) e a quantidade de peças acabadas (QPA) de cada um dos cinco modelos de peças fabricadas. Após essa fase, pesquisou-se a quantidade de matéria-prima necessária para moldar cada um dos cinco modelos (QMPP). As matérias-primas consideradas foram: gel, resina, talco e fibras de vidro em geral. Todos os dados (QPM, QPA e QMPP) foram coletados junto aos arquivos do setor de Planejamento e Controle de Produção e Materiais (PCPM) da unidade estudada. A quantidade de matéria-prima usada durante o mês foi obtida mediante a Equação 1 aplicada, separadamente, a cada um dos cinco modelos de peças (quatro tetos e uma entrejanelas):

$$
M P U=Q P M \times Q M P P
$$

onde MPU $(\mathrm{kg})$ = quantidade de matéria-prima usada no mês; QPM (un) = quantidade de peças moldadas no mês; QMPP $(\mathrm{kg})=$ quantidade de matéria-prima por peça.

Em seguida, foi feita a pesagem das aparas para determinar a quantidade de matéria-prima perdida nas 
duas linhas de produção. No período de 5 de maio a 5 de junho de 2009 foram entregues aos responsáveis planilhas para a pesagem $(\mathrm{kg})$ das aparas livres de contaminação. A pesagem ocorreu em dois pontos da Moldagem e um ponto do Acabamento e considerou os cinco diferentes modelos de peças produzidas.

- Ponto 1 (teto) - Laminação: Todo o papelão usado foi pesado antes (peso inicial) e depois (peso final) da laminação de cada peça. A diferença entre o peso inicial e o peso final correspondeu à quantidade de aparas geradas por um único teto nesse ponto. Após a pesagem, calculou-se a quantidade média $(\mathrm{kg})$ de aparas geradas na laminação de um único teto, independentemente do modelo que estava sendo laminado, uma vez que a área que recebe as aparas é a mesma para os quatro modelos de teto produzidos;

- Ponto 2 (teto e entrejanelas) - Desmoldagem: As rebarbas das laterais maiores dos tetos e de todas as laterais das entrejanelas, depois de removidas, foram pesadas separadamente, para determinar-se a quantidade média $(\mathrm{kg}) \mathrm{de}$ aparas geradas nesse ponto por cada um dos cinco modelos de peças em PRFV produzidos pela unidade;

- Ponto 3 (teto) - Acabamento: Nesse ponto, as rebarbas cortadas das laterais menores dos tetos também foram pesadas, separadamente, para a determinação da quantidade média $(\mathrm{kg})$ de aparas geradas por cada um dos quatro modelos de tetos produzidos.

A somatória das quantidades médias de aparas geradas por cada modelo nos pontos 1 e 2 corresponde à quantidade de aparas geradas na Moldagem (APM). $\mathrm{O}$ ponto 3 , em si, corresponde à quantidade média de aparas geradas no Acabamento (APA). Para auxiliar, organizar e facilitar a quantificação, várias planilhas foram elaboradas e usadas em todas as etapas que envolveram cálculos, tanto a anterior, quanto as que se seguem.

Determinada a quantidade de aparas que cada modelo de peça produz, a quantidade de aparas geradas mensalmente foi obtida com o auxílio das Equações 2 e 3 aplicadas à produção de cada um dos cinco modelos de peças produzidas em todos os meses estudados. Para a determinação da quantidade total de aparas geradas pelos tetos, fez-se a somatória de todas as QAGM (quantidade de aparas geradas na Moldagem) e QAGA (quantidade de aparas geradas no Acabamento) dos quatro modelos de tetos em cada um dos meses analisados.

$$
Q A G M=Q P M x A P M
$$

$$
Q A G A=Q P A x A P A
$$

onde QAGM $(\mathrm{kg})$ = quantidade de aparas geradas na moldagem; QPM (un) = quantidade de peças moldadas; $\mathrm{APM}(\mathrm{kg})$ = quantidade média de aparas geradas na moldagem de uma única peça; QAGA $(\mathrm{kg})=$ quantidade de aparas geradas no acabamento; QPA (un) = quantidade de peças acabadas; APA $(\mathrm{kg})=$ quantidade média de aparas geradas no acabamento de uma única peça.

Os resíduos de embalagens vazias foram calculados com base na matéria-prima requisitada do estoque (MPR) - dados levantados junto ao PCPM. Para o cálculo do peso $(\mathrm{kg})$ aproximado dos principais resíduos gerados no processo, as Equações 4 e 5 foram aplicadas na quantificação dos resíduos de embalagem dos seguintes materiais: resina; catalisador; gel; selador; limpador; desmoldante líquido; massa de fio moído; solução de limpeza; massa plástica; cera desmoldante e massa rápida. Essas equações foram aplicadas a cada um desses materiais e em todos os 12 meses estudados:

$$
\begin{gathered}
Q R=M P R / P L \\
P R=Q R \times P E
\end{gathered}
$$

onde QR (un) = quantidade de resíduos (latas, bombonas, tambores, baldes); MPR ( $\mathrm{kg}$ ou $\mathrm{L})$ = quantidade de matéria-prima requisitada; PL $(\mathrm{kg}$ ou $\mathrm{L})=$ peso líquido de cada embalagem; PR $(\mathrm{kg})=$ peso de resíduos de embalagem; $\mathrm{PE}(\mathrm{kg})=$ peso de suas embalagens vazias.

As quantidades de resíduos de papelão e plástico foram determinadas considerando-se somente a MPR, uma vez que todo o plástico e papelão requisitado do estoque é descartado como resíduo após o uso.

Para finalizar, a somatória da geração mensal dos resíduos de embalagem, das aparas e do consumo de papelão e de plástico corresponde à quantidade aproximada dos resíduos sólidos gerados no processo de Moldagem e Acabamento em PRFV no mês analisado.

Ao término do diagnóstico foram apresentadas à empresa estudada ações que contribuiriam para a redução de resíduos, as quais poderão ser implementadas pela unidade estudada. Essas ações foram planejadas com base nos resultados obtidos, na revisão da literatura e, ainda, em experiências de sucesso de outras empresas.

\section{Resultados e discussões}

Na unidade estudada, a fabricação de peças em PRFV usa moldes abertos. Na laminação dos tetos, a unidade faz uso de uma tecnologia própria na qual uma pistola picadora foi adaptada a uma máquina, formando uma laminadora semiautomática. O processo de laminação é similar ao apresentado por Matheus 
(2002). A moldagem aberta caracteriza-se como uma tecnologia mais barata que processos mais modernos, além de permitir uma maior liberdade de design e de ser boa para produzir peças grandes e em pequena escala (JACOB, 2002). Em contrapartida, na moldagem aberta o ritmo de produção é baixo e a mão de obra é intensa. Todos esses fatores foram observados neste estudo: a produção de peças em PRFV na fábrica é, em média, de 358 peças.mês ${ }^{-1}$, requer muita mão de obra e as peças produzidas são grandes (tetos - 10,5 m × 2,5 m; entrejanelas - 12,33 m). Embora a unidade faça uso de apenas 12 moldes, a variação no comprimento das peças moldadas pode chegar a centenas de tamanhos diferentes, o que só é possível devido à liberdade proporcionada pela moldagem aberta. Entretanto, o uso de moldes abertos é responsável por grandes impactos ambientais, principalmente, no que se refere ao consumo e perda de matérias-primas e à geração de resíduos.

A Tabela 1 apresenta dados da produção mensal de peças em PRFV, da matéria-prima usada para produzi-las, da quantidade de aparas geradas, além do percentual de perdas de matéria-prima na forma de aparas.

No período em que a pesquisa foi aplicada, a fábrica produziu, em média, 316 tetos e 42 entrejanelas por mês. Observa-se que o consumo de matéria-prima e a quantidade de aparas são significativos, o que se deve, basicamente, à moldagem aberta, uma vez que nesse processo de laminação a formação de aparas é intensa, o que resulta na geração de resíduos. A perda de matéria-prima na forma de aparas nesse tipo de moldagem, segundo Milan e Grazziotin (2008), pode ser de $15 \%$ a $25 \%$, dependendo da geometria da peça. $\mathrm{Na}$ fabricação das entrejanelas, por exemplo, que são peças mais complexas, a perda de matéria-prima (30\%) é três vezes maior que na produção dos tetos (9\%), peças mais simples.

A Figura 2 mostra, a título de comparação, os moldes das entrejanelas e do teto - nas fotos é possível notar a diferença de complexidade entre eles. Embora o processo de produção dos tetos seja do tipo spray-up, o uso de uma laminadora semiautomática aliado ao fato de o teto ser uma peça extremamente simples explica o percentual de perda de $9 \%$, inferior ao mínimo de $15 \%$, conforme relatado.

A Tabela 2 apresenta dados da geração e destinação dos principais resíduos sólidos no período estudado. Os números referem-se à sucata vendida (tambores, latas, baldes e bombonas), aos resíduos devolvidos aos fornecedores (bombonas), às aparas de PRFV e aos plásticos e papelões contaminados.

Note-se que $67 \%$ dos resíduos gerados tiveram como destino final o aterro industrial. Do total de resíduos classe IIA depositados no aterro, $68 \%$ (74,17 ton) são aparas. Já o gráfico da Figura 3 mostra que as aparas correspondem a 45,37\% de todos os resíduos gerados no processo. Os resíduos de papelão e plástico juntos, cuja quantidade gerada somente se deve ao uso de moldes abertos, correspondem a $21,65 \%$ de todos os resíduos do processo.

A Figura 4 apresenta algumas imagens do uso do papelão no processo de Moldagem e Acabamento em PRFV. Em alguns pontos, como os da Figura 4b, o papelão é trocado várias vezes durante um dia de trabalho.

Tabela 1. Produção de peças em PRFV; matéria-prima usada, quantidade de aparas geradas e percentual de perda de matériaprima no processo de Moldagem e Acabamento em PRFV da unidade estudada.

\begin{tabular}{ccccccccc}
\hline & \multicolumn{4}{c}{ TETOS } & \multicolumn{3}{c}{ ENTREJANELAS } \\
\cline { 2 - 9 } Mês/ano & $\begin{array}{c}\text { QPM } \\
\text { (un) }\end{array}$ & $\begin{array}{c}\text { MPU } \\
\text { (ton) }\end{array}$ & $\begin{array}{c}\text { QAG } \\
\text { (ton) }\end{array}$ & $\begin{array}{c}\text { PMP } \\
(\boldsymbol{\%})\end{array}$ & $\begin{array}{c}\text { QPM } \\
\text { (un) }\end{array}$ & $\begin{array}{c}\text { MPU } \\
\text { (ton) }\end{array}$ & $\begin{array}{c}\text { QAG } \\
\text { (ton) }\end{array}$ & $\begin{array}{c}\text { PMP } \\
\text { (\%) }\end{array}$ \\
\hline mai/08 & 382 & 75,32 & 7,05 & 9 & 29 & 0,80 & 0,24 & 30 \\
jun/08 & 386 & 76,95 & 7,21 & 9 & 121 & 3,32 & 1,00 & 30 \\
jul/08 & 494 & 99,80 & 8,95 & 9 & 82 & 2,25 & 0,68 & 30 \\
ago/08 & 375 & 74,72 & 6,94 & 9 & 64 & 1,76 & 0,53 & 30 \\
set/08 & 463 & 92,39 & 8,53 & 9 & 24 & 0,66 & 0,20 & 30 \\
out/08 & 352 & 70,41 & 6,43 & 9 & 63 & 1,73 & 0,52 & 30 \\
nov/08 & 259 & 52,50 & 4,82 & 9 & 34 & 0,93 & 0,28 & 30 \\
dez/08 & 310 & 63,17 & 5,82 & 9 & 23 & 0,63 & 0,19 & 30 \\
jan/09 & 281 & 56,72 & 5,21 & 9 & 13 & 0,36 & 0,11 & 30 \\
fev/09 & 157 & 32,18 & 2,94 & 9 & 4 & 0,11 & 0.03 \\
mar/09 & 149 & 30,55 & 2,71 & 9 & 31 & 0,85 & 0,26 & 30 \\
abr/09 & 185 & 36,81 & 3,42 & 9 & 12 & 0,33 & 0,10 \\
Média mensal & $\mathbf{3 1 6}$ & $\mathbf{6 3 , 4 6}$ & $\mathbf{6 , 0 5}$ & $\mathbf{9}$ & $\mathbf{4 2}$ & $\mathbf{1 , 1 4}$ & $\mathbf{0 , 3 4}$ & 30 \\
\hline
\end{tabular}

Legenda: QPM - quantidade de peças moldadas; MPU - matéria-prima usada na moldagem; QAG - quantidade de aparas e rebarbas geradas; PMP - percentual de perda de matéria-prima na forma de aparas de PRFV. 

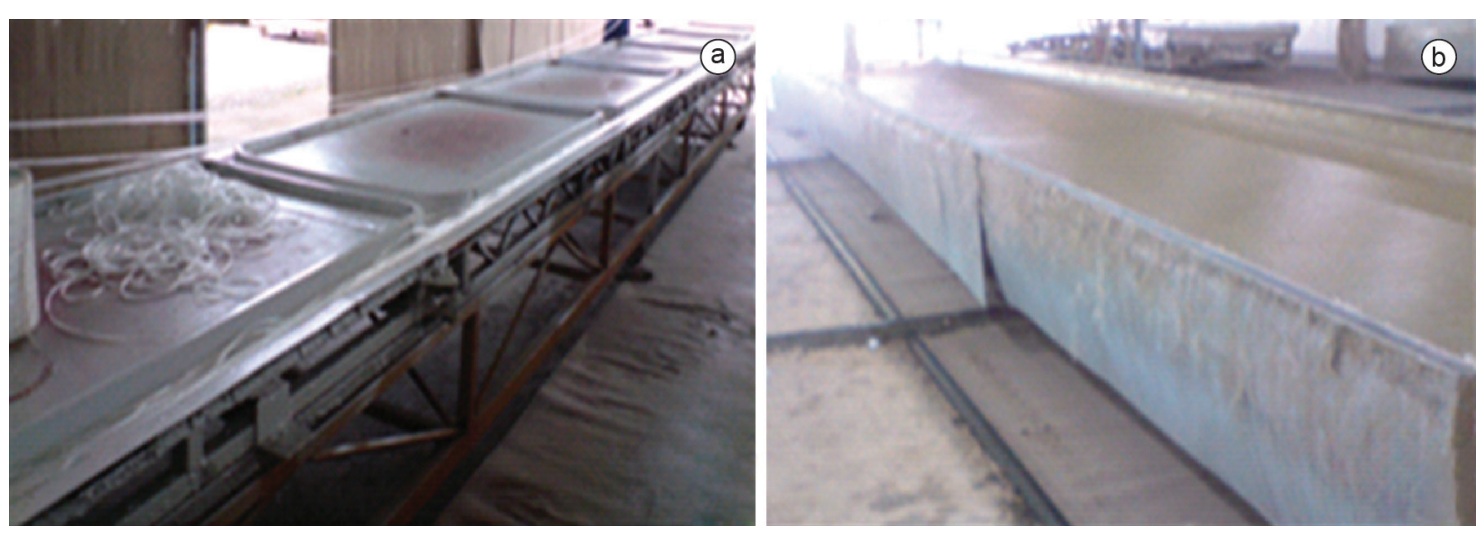

Figura 2. Moldes usados no processo (fevereiro de 2010): a) entrejanelas; b) teto.

Tabela 2. Produção de resíduos sólidos (ton) no processo de Moldagem e Acabamento em PRFV da unidade estudada.

\begin{tabular}{|c|c|c|c|c|c|c|}
\hline \multirow[b]{2}{*}{ Mês/ano } & \multicolumn{2}{|c|}{ RECICLAGEM/REUSO } & \multicolumn{3}{|c|}{ ATERRO CLASSE IIA } & \multirow{2}{*}{$\begin{array}{l}\text { TOTAL DE } \\
\text { RESÍDUOS DO } \\
\text { PROCESSO }\end{array}$} \\
\hline & $\begin{array}{c}\text { Sucata } \\
\text { vendida }\end{array}$ & $\begin{array}{c}\text { Resíduos } \\
\text { devolvidos }\end{array}$ & $\begin{array}{c}\text { Plástico } \\
\text { transparente }\end{array}$ & $\begin{array}{c}\text { Papelão } \\
\text { ondulado }\end{array}$ & $\begin{array}{c}\text { Aparas de } \\
\text { PRFV }\end{array}$ & \\
\hline mai/08 & 4,94 & 0,09 & 0,09 & 2,80 & 7,29 & 15,21 \\
\hline jun/08 & 5,40 & 0,12 & 0,11 & 3,26 & 8,21 & 17,09 \\
\hline jul/08 & 7,07 & 0,15 & 0,12 & 5,20 & 9,62 & 22,16 \\
\hline ago/08 & 5,69 & 0,15 & 0,09 & 4,36 & 7,47 & 17,75 \\
\hline set/08 & 6,16 & 0,16 & 0,17 & 4,96 & 8,73 & 20,17 \\
\hline out/08 & 5,10 & 0,11 & 0,11 & 4,05 & 6,95 & 16,32 \\
\hline nov/08 & 3,65 & 0,08 & 0,07 & 2,69 & 5,10 & 11,60 \\
\hline $\mathrm{dez} / 08$ & 4,05 & 0,08 & 0,08 & 2,29 & 6,01 & 12,51 \\
\hline jan/09 & 4,15 & 0,07 & 0,06 & 1,65 & 5,32 & 11,25 \\
\hline fev/09 & 1,94 & 0,04 & 0,04 & 1,06 & 2,97 & 6,05 \\
\hline mar/09 & 2,12 & 0,04 & 0,05 & 0,99 & 2,97 & 6,17 \\
\hline $\mathrm{abr} / 09$ & 2,48 & 0,05 & 0,05 & 1,01 & 3,51 & 7,10 \\
\hline TOTAL & 52,76 & 1,13 & 1,05 & 34,32 & 74,14 & 163,39 \\
\hline Média mensal & \multicolumn{2}{|c|}{$33 \%$} & & $67 \%$ & & \\
\hline
\end{tabular}
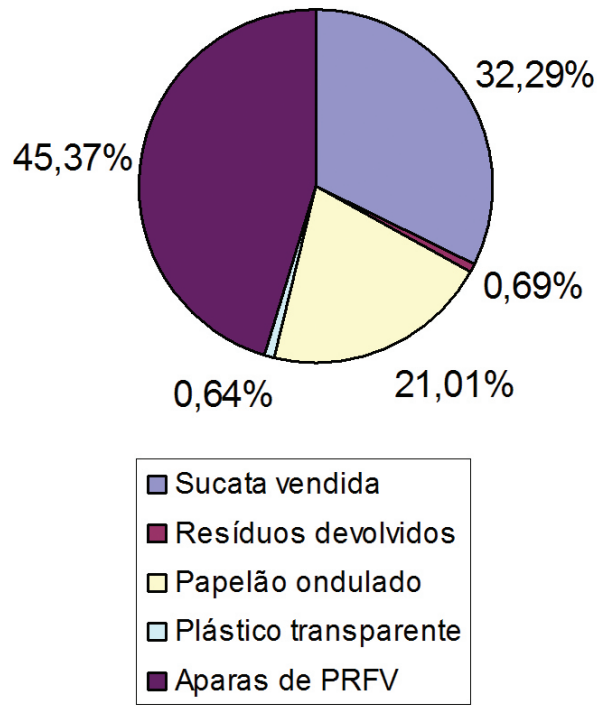

Figura 3. Percentual de resíduos gerados no processo de Moldagem e Acabamento em PRFV em todo o período estudado.
No período de coleta de dados, a unidade fabril estudada deu início à eliminação do uso do plástico polietileno transparente por meio de sua substituição por lonas e anteparos de PRFV. Além disso, quando possível, os plásticos são reutilizados, sendo descartados somente depois de contaminados. Entretanto, a fábrica não faz uso de nenhuma medida que reduza de maneira significativa a quantidade ou o volume desse resíduo. A Figura 5 apresenta uma imagem dos resíduos do processo de Moldagem e Acabamento em PRFV, na qual observa-se o grande volume de aparas e de papelão e plástico contaminados.

Em vista dessas constatações, pode-se afirmar que a principal fonte de geração de resíduos no processo de Moldagem e Acabamento em PRFV na fábrica estudada relaciona-se ao uso de moldes abertos, um processo de laminação tradicional, de baixa tecnologia e considerado sujo em termos ambientais.

A geração desses resíduos implica tanto em prejuízos ambientais como econômicos. O fato de serem resíduos extremamente volumosos aumenta 

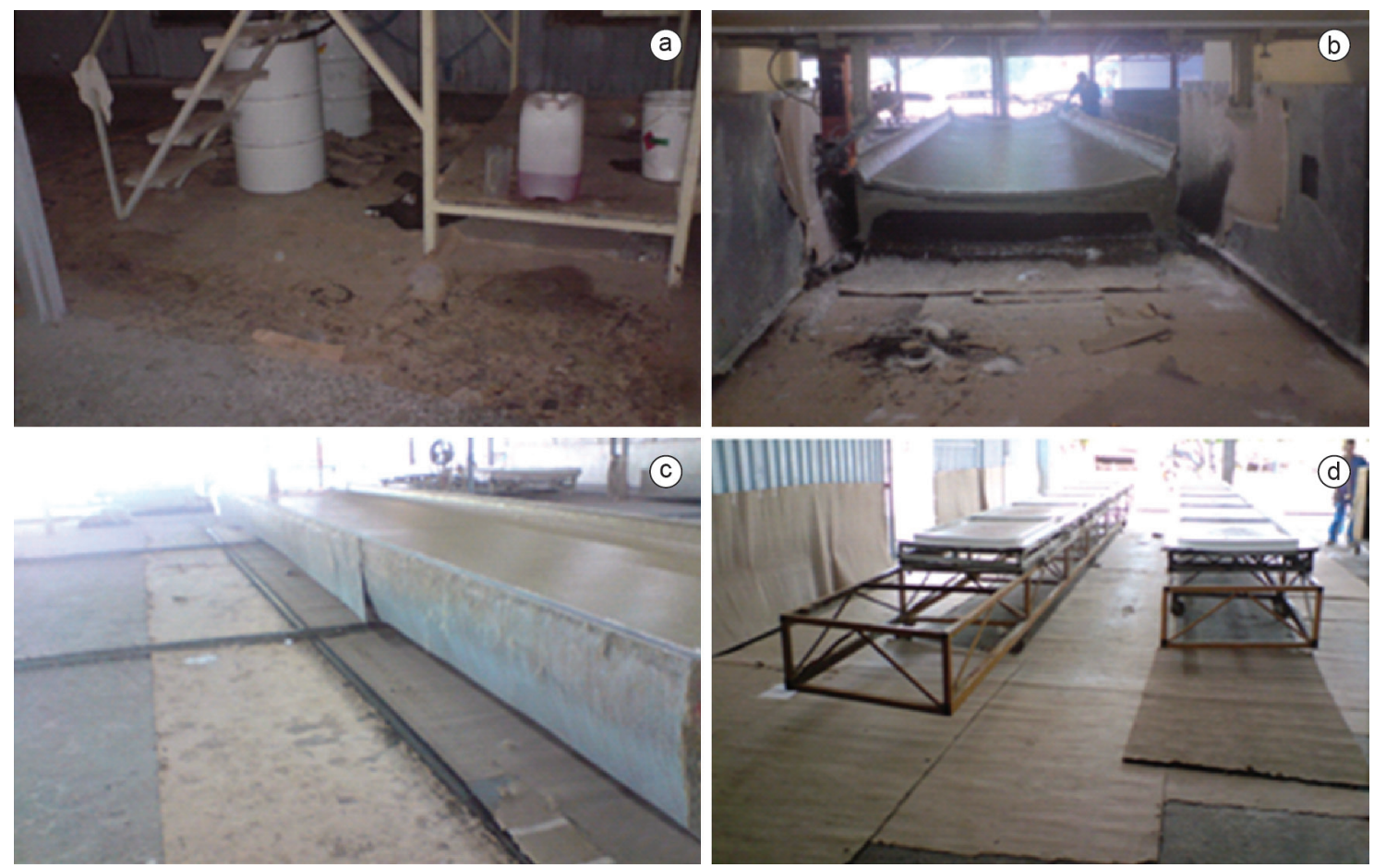

Figura 4. Uso de papelão ondulado no processo de Moldagem e Acabamento em PRFV (fevereiro e maio de 2009): a) piso sob os tambores de resina; b) paredes da laminadora semiautomática e piso sob ela; c) piso em volta e embaixo do molde do teto; d) piso e paredes na laminação das entrejanelas.

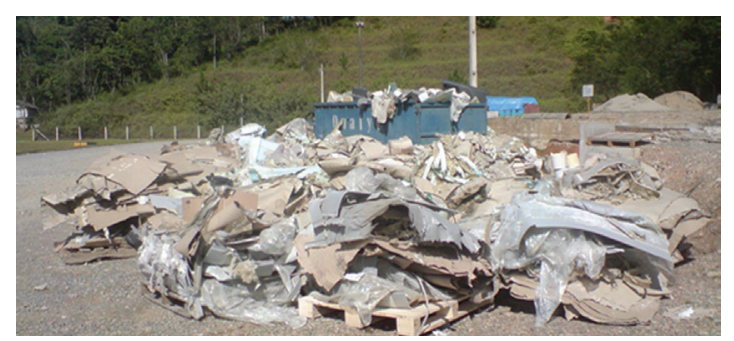

Figura 5. Resíduos do processo de Moldagem e Acabamento em PRFV (maio de 2009).

os gastos da empresa com o transporte, além de potencializar os prejuízos ambientais relacionados a esse procedimento. Já a disposição desses resíduos em aterros contribui, por exemplo, para acelerar o fim de sua vida útil. Soma-se a isso o fato de as aparas não serem biodegradáveis por se constituírem, basicamente, de resinas e de fibras de vidro. Em se tratando da reciclagem, medida que poderia impedir que tais resíduos fossem destinados a aterros, a contaminação do papelão e do plástico, por exemplo, a inviabiliza. Além disso, a unidade não adota nenhuma medida de reciclagem relacionada às aparas do processo.

Embora a reciclagem seja uma medida ambiental consagrada e comprovadamente de sucesso, programas como a Política dos 3 Rs, os PGR, a P+L, dentre outros, priorizam a redução de resíduos já na sua fonte geradora, ou seja, antes de se pensar em reciclar, reutilizar, tratar ou dispor em aterros devese, primeiramente, buscar meios de não gerar tais resíduos. Autores como Layrargues (2002), Vilhena e Politi (2005) e Sperandio e Gaspar (2007) defendem tal princípio e o destacam como parte da Política dos 3 Rs, reconhecida internacionalmente e que enfatiza a moderação do consumo. De acordo com esses autores, causa menos impacto evitar a geração de resíduo do que reutilizar ou reciclar os materiais após o seu descarte. Sperandio e Gaspar (2007) citam o bom exemplo da recirculação total das águas de um processo industrial como uma importante forma de reduzir o consumo desse recurso e, consequentemente, a geração de efluentes industriais. Nessa linha de pensamento, afirma-se que a empresa aqui estudada precisa, preferencialmente, tentar eliminar ou amenizar a geração de seus principais resíduos, no caso, as aparas de PRFV. A redução de resíduos na fonte geradora consiste medida preventiva e, conforme Tocchetto (2005), pode ocorrer por meio de mudanças no uso de matérias-primas e insumos, de modificações no processo produtivo ou da adoção de novas tecnologias, dentre outras.

Dessa forma, a solução com resultados mais efetivos para a unidade estudada consiste na migração para um processo produtivo mais limpo e mais moderno, como o sugerido por Milan e Grazziotin (2008). Os referidos autores, ao realizarem a implantação da $\mathrm{P}+\mathrm{L}$ em uma empresa do setor PRFV, concluíram que a moldagem 
do tipo aberta era a responsável pela grande geração de resíduos. Diante disso, propuseram a migração para o RTM light (Resin, Transfer Moulding), um processo de laminação mais moderno e que usa moldes fechados. Milan e Grazziotin (2008) constataram que a perda de material na forma de aparas, que antes era de $19,5 \%$ ao mês, após a mudança no processo produtivo sofreu uma queda de $80 \%$, passando a ser de apenas $4 \%$. Nessa mesma direção, de acordo com Lima (2006), os transformadores de moldagem aberta devem começar a repensar seus negócios, uma vez que existem montadoras que não permitem mais a compra de peças de moldes abertos. É preciso investir em soluções de reciclagem e usar processos com menores perdas, tais como RTM, infusão, pultrusão e outros. Destaca-se que empresas que promovem a redução de seus resíduos já na sua fonte geradora não só contribuem para a promoção da qualidade ambiental como também melhoram a sua imagem no mercado, atendem às normas e legislações vigentes, atraem novos mercados consumidores e reduzem os custos com o gerenciamento de seus resíduos.

\subsection{O desperdício de materiais}

Outra fonte de geração de resíduos diagnosticada na unidade estudada diz respeito ao uso irracional de materiais por parte de alguns funcionários. A Figura 6 mostra recipientes que ficam abertos durante toda a jornada de trabalho, mesmo quando não estão sendo usados. Nessas condições, esses produtos podem ter suas propriedades comprometidas devido a evaporação ou catalisação. Às vezes, as massas e ceras catalisadas são recuperadas, mas, quando isso não é possível, embalagens são descartadas contendo sobras significativas dos produtos que acondicionam.

Outra forma de desperdício refere-se ao uso excessivo de materiais. Na Figura 7a, a quantidade de massa plástica catalisada poderia ser menor se ela não tivesse sido preparada em excesso. Frequentemente são encontrados papelões, como os da referida figura, contendo quantidades consideráveis de massa catalisada nos coletores de resíduos do setor. $\mathrm{Na}$ Figura $7 b$, a sobra de tecido de fibra de vidro poderia ser menor se o corte tivesse sido feito mais próximo ao molde.

Falhas mecânicas ou humanas resultam, frequentemente, em perdas significativas de matériaprima, como o fio roving (Figura 8), ou, ainda, em uma geração excessiva de aparas.

Destaca-se que em medições para determinar a quantidade de aparas geradas constatou-se que para laminar um único teto a pistola lança de 3 a $4 \mathrm{~kg}$ de aparas nas paredes da laminadora e no piso próximo de onde se encontra, uma falha mecânica elevou para $8 \mathrm{~kg}$ a quantidade dessas aparas.

Uma falha humana na delimitação do comprimento de um teto resultou na rebarba mostrada na Figura 9
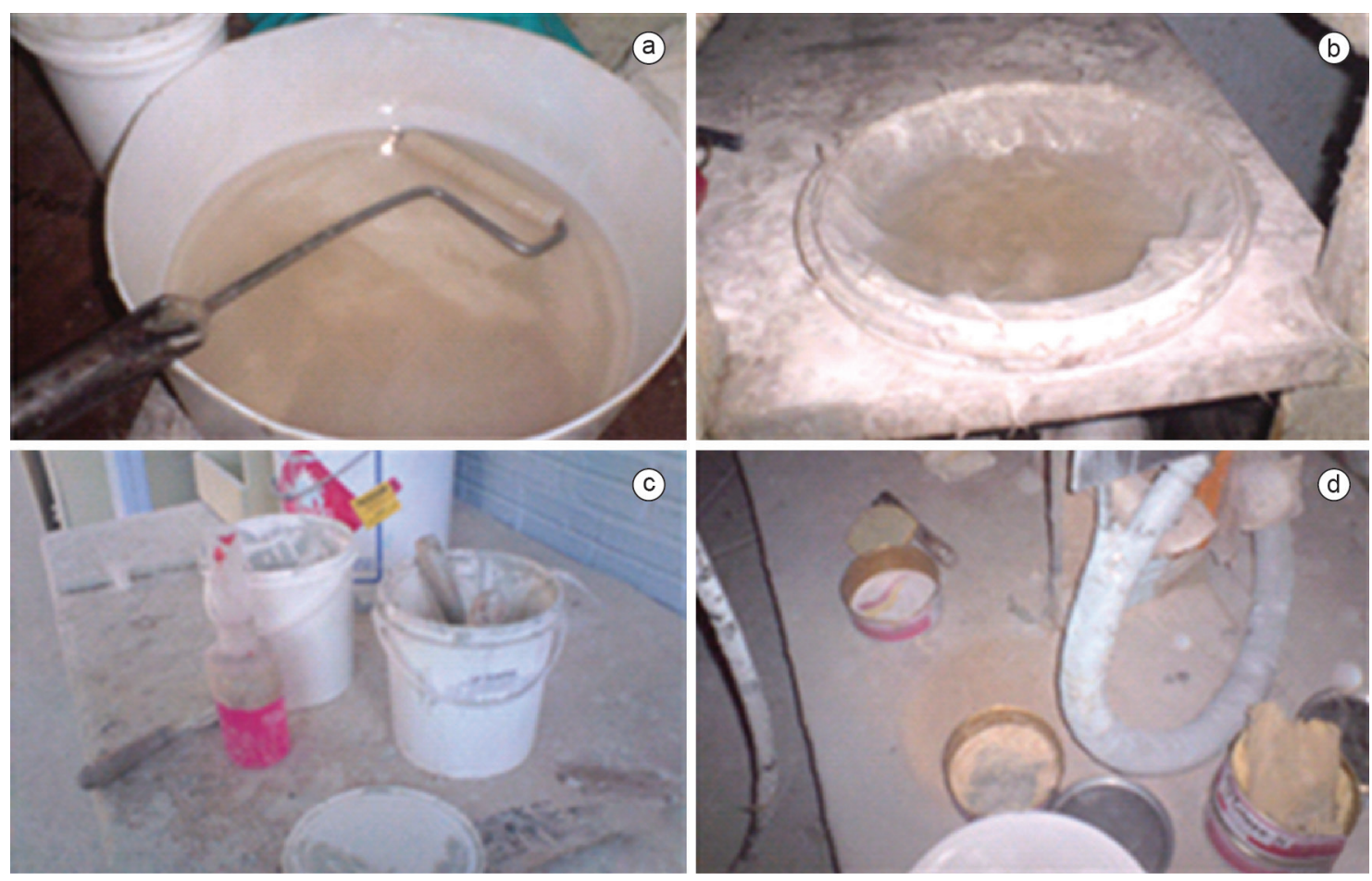

Figura 6. Recipientes abertos durante, praticamente, toda a jornada de trabalho (fevereiro e março de 2009): a-b) solução de limpeza (acetona); c) massa plástica; d) cera desmoldante. 

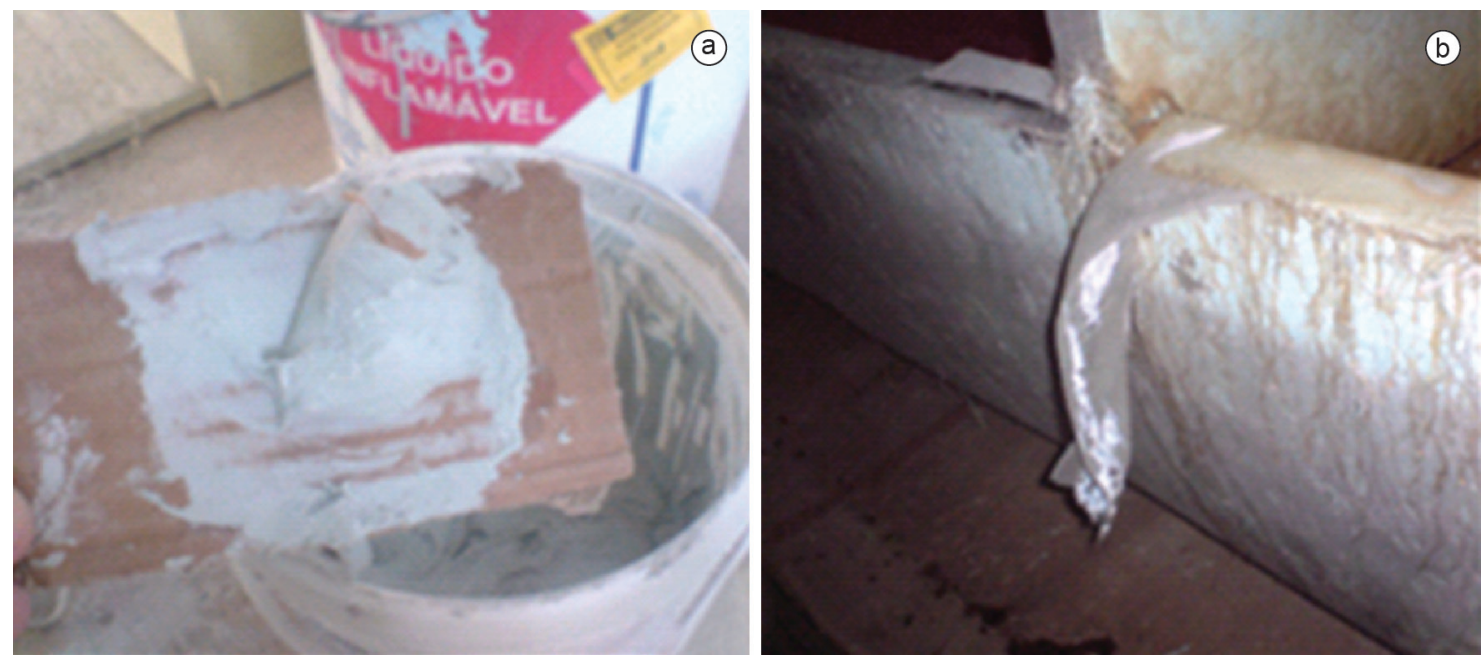

Figura 7. Desperdício decorrente do uso ou preparo excessivo de materiais (abril de 2009): a) massa plástica; b) sobra de tecido de fibra de vidro.
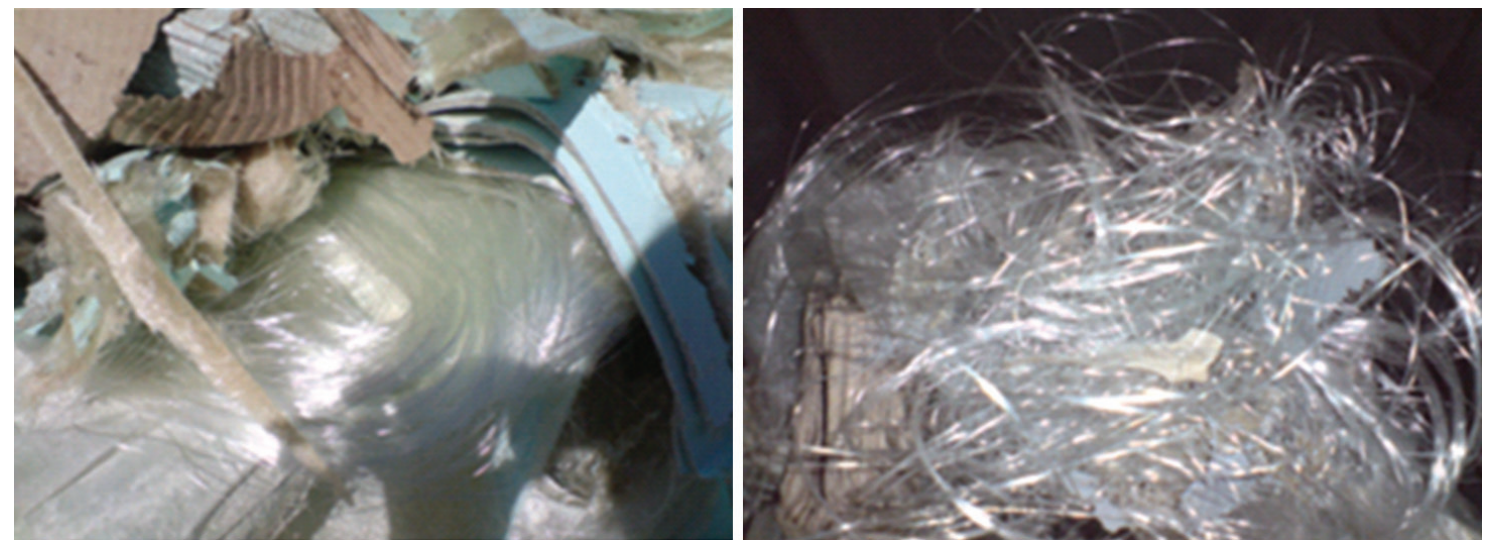

Figura 8. Perda de fio roving por problemas mecânicos na laminadora ou por falhas humanas (fevereiro e abril de 2009).

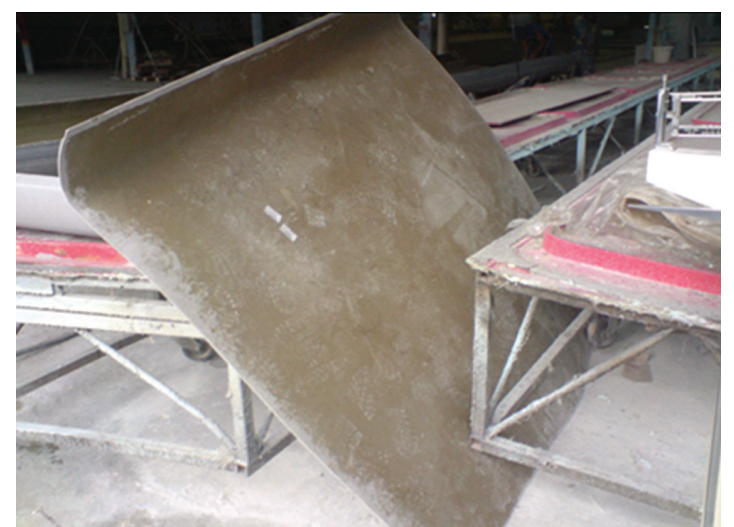

Figura 9. Rebarba gigante decorrente de um erro de delimitação no comprimento de um teto (maio de 2009).

que, em seu tamanho normal, deve ser de 5 a 8 vezes menor.

Constatou-se que a disposição de embalagens no pátio de armazenagem temporária de resíduos localizado dentro da empresa, ainda contendo sobras dos produtos que acondicionavam, possibilita que bombonas sejam dispostas como resíduos contendo pequenas quantidades de catalisador (Figura 10), um produto perigoso, altamente inflamável, oxidante, corrosivo e nocivo para o meio ambiente.

Destacamos que o catalisador não deve ficar exposto como na Figura 10 e que o produto deveria ter sido utilizado até o final. Essas bombonas, com ou sem sobras de produto, permanecem ali, ao ar livre, até o momento de serem vendidas para reciclagem. De acordo com as Fichas de Informações de Segurança do catalisador, a exposição repetida ao produto e/ou se ele for inalado ou ingerido pode provocar sérios danos aos olhos, à garganta, ao nariz e às vias respiratórias, além de dores de cabeça, náuseas, sonolência e vertigens. Na pele, pode provocar secura e fissuras (MEKOL, 2008; CARPLAST, 2011; WEG, 2012).

As formas de desperdício relatadas contribuem para a geração de resíduos e são decorrentes do uso irracional de matéria-prima, de hábitos de trabalho "enraizados" e da falta de Educação Ambiental. De 

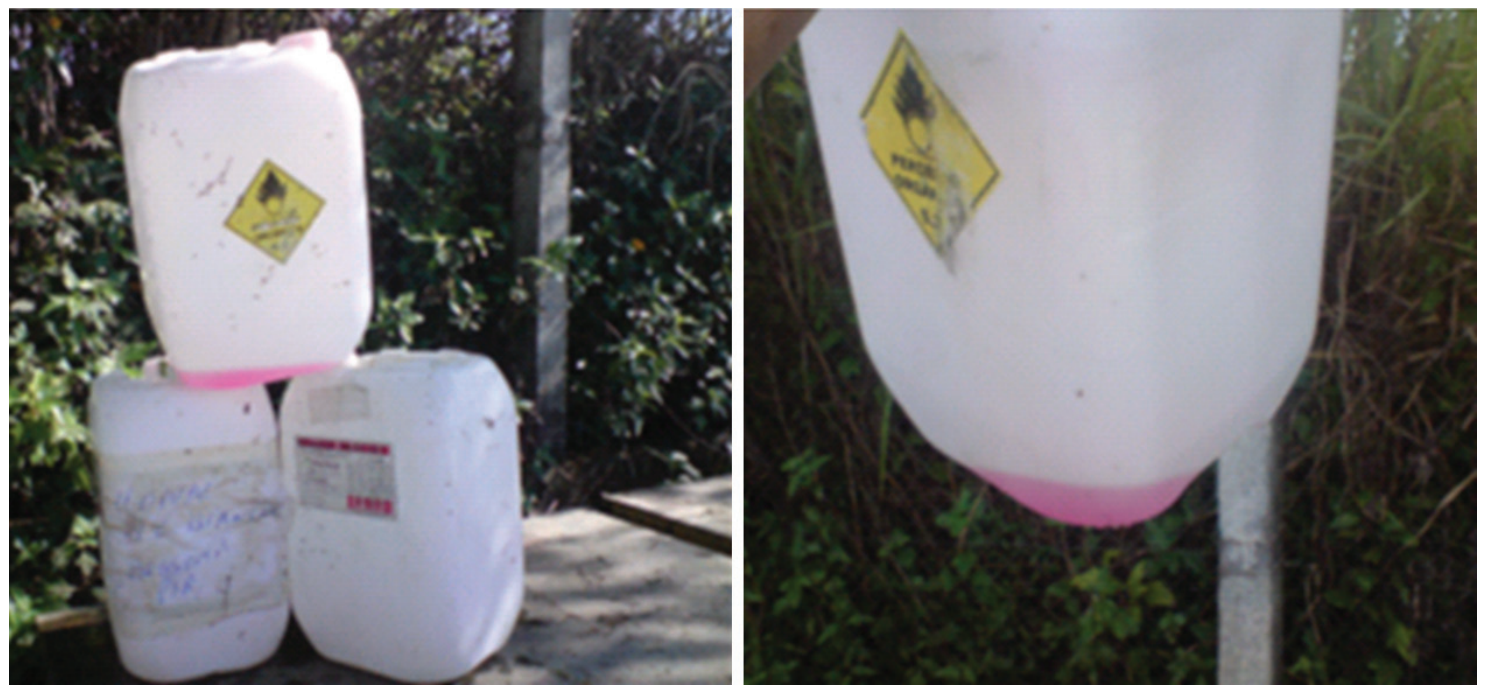

Figura 10. Bombonas com sobras de catalisador dispostas como resíduos (março e junho de 2009).

acordo com Pinto (2002), fatores como a falta de treinamento dos operadores, o manuseio e utilização inadequada de matérias-primas e a ausência de sensibilidade ambiental podem contribuir para a geração de resíduos. Os funcionários da unidade foram orientados a não desperdiçar materiais considerando apenas os benefícios econômicos dessa prática, sem qualquer perspectiva da conscientização ambiental. É importante frisar que para uma empresa reduzir desperdícios implica em amenizar não só os prejuízos ambientais como também diminuir os gastos que giram em torno desses resíduos. Evitar desperdícios implica, ainda, em retardar a aquisição de novos materiais, cujo processo de produção, armazenagem e transporte também envolve impactos ambientais. Sendo assim, a empresa que evita desperdícios contribui para a melhoria da qualidade ambiental, seja pela redução na geração de resíduos, seja pela diminuição na aquisição de novos materiais.

Informações de caráter ambiental referentes ao consumo e uso racional de materiais podem ser passadas aos funcionários da empresa por meio de ações preventivas de Educação Ambiental (EA), que são comprovadamente eficientes e requerem poucos investimentos. A Educação Ambiental, ao construir valores, conceitos, habilidades e atitudes, contribui para a implementação de um padrão distinto do vigente, pautado numa nova ética da relação sociedade-natureza (LOUREIRO, 2002).

Embora a adoção de tecnologias mais limpas, a princípio, apresente resultados mais significativos em termos de redução da quantidade, do volume e da periculosidade dos resíduos, neste estudo buscou-se dar uma atenção especial à Educação Ambiental como ação pedagógica com vistas a amenizar o desperdício registrado na fábrica.

\subsection{A Educação Ambiental como forma de combate ao desperdício}

Embora a EA esteja mais fortemente presente nas instituições de ensino, ela vem se desenvolvendo de forma abrangente em outras instituições da sociedade, dentre elas as organizações empresariais. Um exemplo de bons resultados da inserção da EA nas empresas são os obtidos por Coutinho et al. (2009, 2011) em uma indústria automobilística que, após a implantação do método de capacitação denominado Dojo Ambiental, apresentou um decréscimo em seus índices de não conformidades ambientais. De acordo com os autores, no primeiro semestre de 2006, antes do Dojo, foram registradas pela empresa estudada 52 não conformidades Resíduos e 74 não conformidades Produtos Químicos. Um ano após o início do treinamento, houve uma redução significativa e os índices de não conformidade passaram a 10, para Resíduos, e 16, para Produtos Químicos.

Existem diversas atividades de EA que podem ser executadas em ambientes fabris. Dentre elas citam-se palestras, treinamentos, oficinas, dinâmicas de grupo, entre outras. A periodicidade dessas atividades deve ser determinada de acordo com a necessidade da empresa e com a disponibilidade de seus funcionários, de forma a não prejudicar o seu funcionamento. Entretanto, ressalta-se que as atividades de EA devem ocorrer mais de uma vez por ano. Recomenda-se ainda que tenham, no mínimo, de acordo com Coutinho et al. (2011), idealizadores do Dojo Ambiental, um total de oito horas de duração/ano (quatro horas a cada semestre), sendo três horas e meia para o treinamento e visita ao chão de fábrica e meia hora para a aplicação de um teste. Atividades uma vez por ano e durante poucas horas não oportunizam, aos participantes, o aprofundamento e a assimilação das 
questões ambientais. Para que apresente resultados significativos, a EA deve ser realizada de forma contínua, de modo a caracterizar-se como uma aprendizagem permanente, afirmando valores e ações que contribuam para a transformação humana e social e para a preservação ecológica (BARRETO; SILVA; PÁDUA, 2008).

Nesse sentido, o estudo aqui em destaque sugere algumas atividades de EA que poderão ser implementadas não somente pela unidade estudada como também por qualquer outra indústria. As atividades devem ser ministradas por pessoas devidamente qualificadas. Algumas delas, porém, podem ser ministradas por funcionários da empresa, desde que eles atuem diretamente com as questões ambientais da empresa e tenham recebido preparo e treinamento adequados. Ressalta-se que a unidade fabril estudada não dispõe de nenhum funcionário que atue com as suas questões ambientais.

Embora as atividades de EA devam ser específicas para os problemas de cada empresa, a inserção de outros temas como: Desenvolvimento Sustentável; Tecnologias Limpas; Poluição; Cidadania e outros ampliaria a visão dos empregados, podendo ter reflexos positivos no seu comportamento dentro e fora da empresa (BARRETO; SILVA; PÁDUA, 2008). Esses temas podem ser tratados, juntamente com os de interesse, por meio de palestras, dinâmicas, grupos de discussões, oficinas e outros, distribuídos ao longo do ano. Recomenda-se que sejam dedicadas de nove a 12 horas por ano a esses tipos de atividade, que podem ser estendidas a toda a fábrica. Quanto aos palestrantes, preferencialmente devem ser convidados de outras instituições, em especial daquelas que atuam na área ambiental.

Devido aos bons resultados alcançados pelo método de capacitação Dojo Ambiental, esta pesquisa propõe o desenvolvimento desse método, não só na unidade estudada como também em outras empresas que registrem desperdícios, desde que feitas as devidas adaptações. Embora o Dojo Ambiental aqui proposto trabalhe um único tema (Consumo e Desperdício de Materiais) e seja referente ao processo de Moldagem e Acabamento em PRFV, temas diversos podem ser tratados por meio dessa capacitação, permitindo, assim, que o Dojo possa ser estendido a outros setores ou processos produtivos da empresa. Entretanto, conforme recomendado por Coutinho et al. (2009), é importante que o número de temas não exceda a três, de forma a não dificultar o processo ensino/aprendizagem. A metodologia aqui proposta, fundamentada na ação e participação, utiliza ao máximo o potencial de aprendizagem e o interesse no conteúdo e

[...] possibilita o desenvolvimento da consciência ambiental através do estímulo da curiosidade, da construção do conhecimento e da realização prática e quantificação de conceitos muitas vezes abstratos (COUTINHO et al., 2011, p. 65).
Dessa maneira, quanto mais temas trabalhados, maior a possibilidade de o objetivo do método não ser alcançado. A Figura 11 apresenta uma imagem do painel móvel (com rodas) usado no Dojo, com o qual Coutinho et al. (2009) trabalharam três temas: Coleta Seletiva, Gestão de Produtos Químicos e Água e Energia. Destaca-se que o uso de um painel móvel permite que a capacitação aconteça em qualquer lugar da fábrica, inclusive onde os problemas ocorrem de fato. Assim, segundo os autores, há uma melhor visualização do problema e uma maior assimilação por parte dos funcionários sob capacitação.

As turmas de capacitação devem ser pequenas, no máximo 15 pessoas, e homogêneas quanto ao grau de escolaridade e área de atuação dentro da empresa. De acordo com Barreto, Silva e Pádua (2008) e Coutinho et al. (2011), turmas grandes podem dificultar que todos participem das dinâmicas de grupo. É importante que o número de turmas, de formadores (treinadores) e o período de duração estejam de acordo com o quadro funcional e com as necessidades da empresa. O Dojo Ambiental deve ser oferecido semestralmente e não deve se estender por muitos dias. Com essa periodicidade, os resultados alcançados por Coutinho et al. (2009) foram bastante significativos, uma vez que após um ano de aplicação do Dojo Ambiental, de acordo o autor supracitado, houve uma redução nos índices de não conformidade, que passaram de 52 para 10 (não conformidades Resíduos) e de 74 para 16 (não conformidades Produtos Químicos).

O tempo de duração deve ser proporcional à quantidade de temas abordados no painel, podendo ser de uma hora e 20 minutos para cada tema. Reforça-se que o número de temas tratados no painel não deve exceder três, conforme mostrado na Figura 11, pois do contrário o tempo de duração aumentaria, tornando-se cansativo e podendo, assim, comprometer $\mathrm{o}$ aprendizado.

Quanto ao formador, ele, preferencialmente, deve ser um funcionário da empresa, devidamente preparado,

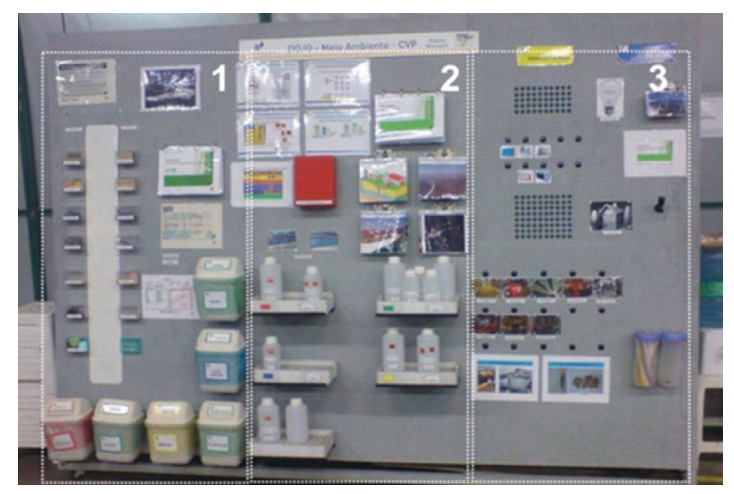

Figura 11. Painel do Dojo Ambiental (COUTINHO et al., 2009, p. 7). 
que tenha conhecimento sobre meio ambiente e atue diretamente com as questões ambientais da empresa. A necessidade de ser um funcionário se justifica pelo seu livre acesso às dependências e documentação.

Em se tratando da capacitação em si, essa se inicia com o formador tratando de assuntos como: o consumismo desenfreado; o descarte precoce, desnecessário e excessivo de materiais; a prioridade da redução e reutilização; e a preferência por materiais que possam ser reutilizados ou reciclados. Os assuntos podem estar ilustrados no painel por meio de imagens, estatísticas, gráficos e outros. O painel deve apresentar, ainda, registros fotográficos do desperdício de materiais dentro da unidade fabril.

Em seguida, dá-se início à dinâmica. $\mathrm{O}$ formador deve entregar aos participantes, previamente organizados em três grupos, ímãs magnéticos com descrições de ações práticas de como se evitar ou corrigir os desperdícios registrados nas fotografias apresentadas no painel. Os grupos decidirão a qual foto cada ímã se refere, fixando-o junto à imagem correspondente. O formador, se necessário, fará as devidas correções enquanto discorre sobre o desperdício como fonte de poluição, suas origens, seus impactos negativos para o meio ambiente e para a empresa, além dos benefícios ambientais do uso racional de materiais, sempre exemplificando as formas de desperdício diagnosticadas na unidade. Ele deve mencionar, ainda, a importância da redução de resíduos na fonte geradora e o quanto isso contribui para a redução final de resíduos.

Em um segundo momento, os participantes podem ser induzidos pelo formador a indicar outras formas de desperdício que presenciam na unidade, sendo éticos e preservando o nome de colegas. Nesse instante, o formador estimula os participantes a indicarem medidas preventivas e/ou corretivas relacionadas aos desperdícios apontados por eles. O formador deve, também, provocar discussões sobre as imagens de embalagens destampadas e/ou contendo sobras de produtos dispostas na área de armazenagem temporária de resíduos. Nesse momento, explica sobre os riscos desse erro grave para o meio ambiente, uma vez que esses são produtos perigosos, deve falar, ainda, sobre a possibilidade de acidentes e derramamentos, sobre o livre acesso de outros funcionários a esses resíduos e sobre a importância ambiental e econômica de se usarem os produtos até o fim. Também poderão ser discutidos: a necessidade de se reutilizarem materiais (papelão, plástico, baldes e outros); os cuidados no manuseio dos materiais, para se evitar perdas; a necessidade de se manter tampados produtos sujeitos à evaporação ou catalisação; e outros. Para finalizar, o grupo deverá ser convidado a dirigir-se à área de armazenagem temporária de resíduos, na tentativa de identificar alguma forma de desperdício.
Após o término do Dojo, os participantes deverão passar por uma autoavaliação. Para tanto, cada participante receberá um questionário com, no máximo, cinco questões fechadas por tema tratado no painel do Dojo, lembrando que o número de temas trabalhados no Dojo não deve exceder três. As questões deverão ser de fácil entendimento e referentes aos assuntos tratados durante o treinamento. A importância do número de questões ser pequeno e de elas serem fechadas se deve ao pouco tempo disponível e, principalmente, de acordo com Coutinho et al. (2011), às dificuldades de os adultos aprenderem, considerando que alguns funcionários já não estão mais familiarizados com as técnicas do processo ensino-aprendizagem. Além disso, questões fechadas são mais fáceis de serem apresentadas em gráficos que, por sua vez, poderão ser utilizados em treinamentos futuros. Os resultados ajudarão a identificar os pontos positivos (resultados alcançados) e os pontos fracos do treinamento, ajudando a melhorá-lo a cada aplicação.

A capacitação ambiental aqui proposta tem como objetivo conscientizar e sensibilizar os funcionários em relação ao uso racional de materiais. Espera-se que os participantes adquiram conhecimento e sensibilidade suficientes para, assim, poderem repensar e mudar suas atitudes quanto ao consumo e ao descarte precoce, excessivo e desnecessário de materiais. Dessa forma poderão contribuir para que os desperdícios registrados na unidade decresçam a cada encontro que tenham. Espera-se, ainda, que os participantes entendam que reduzir a quantidade de resíduos é um compromisso importante e permanente, e que diminuir o desperdício depende de cada um deles (FARIAS, 2003).

Recomenda-se que durante o semestre seguinte ao Dojo, seja feita, de forma simples e observacional, uma pequena auditoria referente aos assuntos tratados no Dojo Ambiental. Para tanto, os formadores, a cada 15 dias, deverão escolher, aleatoriamente, um dia da semana para fiscalizar o setor e os coletores de resíduos da unidade, tanto os presentes no chão de fábrica quanto os presentes na área de armazenagem temporária e, assim, buscar detectar algum desperdício: um papelão que poderia ter sido reutilizado; o descarte de grandes quantidades de fibras de vidro; recipientes abertos ou com sobras de produtos; e outros. Para realizar a fiscalização, o formador deve ter em mãos um checklist, e deverá levá-lo a cada auditoria. Finalizada a verificação, o formador fará a contagem das não conformidades e elaborará gráficos que poderão ser usados durante a capacitação. No momento da auditoria, novas fotos poderão ser feitas para a atualização do painel.

Além do Dojo, eventualmente, a empresa pode promover ações ou eventos como: Semana do Meio Ambiente e da Água; passeios ecológicos; gincanas e o que mais julgar necessário. A elaboração e fixação 
de um painel informativo que constem os resultados obtidos com as capacitações, além de qualquer outra informação de caráter ambiental, também deve ser considerada pela unidade.

\section{Conclusões}

$\mathrm{O}$ uso da moldagem aberta para a fabricação de compósitos em PRFV, além de ser a principal fonte de geração de resíduos sólidos no processo analisado, é responsável por grandes perdas de matéria-prima, que implicam tanto em prejuízos ambientais quanto econômicos. Situações como a diagnosticada levam os governos, o mercado e a sociedade a pressionarem as empresas a tornarem seus processos produtivos mais limpos. Assim, empresas que queiram melhorar a sua imagem, atingir novos mercados e atender às normas e legislações precisam incorporar a questão ambiental de forma mais efetiva. Nesse sentido é importante que não apenas a unidade estudada como também outras empresas que adotem processos sujos busquem meios de reduzir a geração de seus resíduos. Ressalta-se que as aparas de PRFV geradas no processo de Moldagem e Acabamento em PRFV e encaminhadas ao aterro industrial não são biodegradáveis e, embora sejam recicláveis, a redução na fonte tem prioridade sobre a reciclagem. Sendo assim, a principal alternativa, sempre que possível, é a adoção de tecnologias mais limpas e mais modernas. As indústrias devem buscar por alternativas que reduzam seus impactos sobre o meio ambiente. O processo de prevenção da poluição deve ser contínuo e melhorado a cada dia.

Além do uso de novas tecnologias, existe a possibilidade das ações pedagógicas da Educação Ambiental, uma importante ferramenta para a conscientização quanto à redução de resíduos, uma vez que é comum deparar-se no setor industrial com o desperdício de materiais. A falta de treinamento operacional aliada à falta de sensibilização ambiental contribui para a geração de resíduos. Na unidade estudada, a exemplo de outras empresas, o descarte precoce de materiais, o descuido no seu manuseio ou o seu uso excessivo são importantes fontes de geração de resíduos. Destaca-se que o desperdício eleva não somente a quantidade de resíduos como também os custos com o gerenciamento desses resíduos. Há ainda um aumento da necessidade e dos custos, com a aquisição de novos materiais, cujo processo de produção também implica em impactos ambientais. O desperdício deve ser combatido. Para tanto, recomenda-se que informações de caráter ambiental relacionadas a ele sejam repassadas aos funcionários, e a maneira mais eficiente de se fazer isso é por meio de ações de Educação Ambiental.

A unidade estudada, a exemplo de tantas outras empresas, não faz uso de Programa de Educação Ambiental. Embora a inserção da Educação Ambiental nas organizações empresariais seja recente, ela é imprescindível para o sucesso de qualquer programa ambiental que uma empresa venha a adotar. Os funcionários precisam ter consciência e sensibilidade de que os resíduos gerados por eles, muitos dos quais destinados a aterros, ficarão lá por muitos e muitos anos, um passivo ambiental nada bem-vindo para as futuras gerações. Funcionários sensibilizados em relação a essas questões, além de contribuírem para a melhoria da qualidade ambiental no seu local de trabalho podem, ainda, estender tal aprendizado ao seu ambiente familiar e social.

\section{Agradecimentos}

À Fundação de Apoio à Pesquisa Científica e Tecnológica do Estado de Santa Catarina - Fapesc; à Universidade da Região de Joinville - UNIVILLE; e à empresa estudada.

\section{Referências}

AMERICAN CHEMISTRY COUNCIL. Automotive. Virginia, 2008. Disponível em:

$<$ http://www.americanchemistry.com/s_plastics/sec_content. asp?CID=1080\&DID=4234>. Acesso em: 22 out. 2008.

BARRETO, L. M. P. A.; SILVA, S. A. H.; PÁDUA, S. M. A contribuição da educação ambiental no processo de gestão ambiental em indústria petroquímica. In: ENCONTRO DA ASSOCIAÇÃO NACIONAL DE PESQUISA E PÓS-GRADUAÇÃO EM AMBIENTE E SOCIEDADE, 4., 2008, Brasília. Anais eletrônicos... Brasília: ANPPAS, 2008. Disponível em: <http://www. anppas.org.br/encontro4/cd/ARQUIVOS/GT9-656545-20080510000751.pdf>. Acesso em: 01 mar. 2010.

CONSELHO EMPRESARIAL BRASILEIRO PARA O DESENVOLVIMENTO SUSTENTÁVEL - CEBDS. Rio de Janeiro, 2008. Disponível em: <http://www. cebds.org.br/cebds/eco-pmaisl-barreiras.asp $>$. Acesso em: 26 maio 2008

CARPLAST LTDA. Ficha de Informação de Segurança de Produtos Químicos. Diadema, 2011. Disponível em: http: <//www.carplast.com.br/fispq/fispq_carplast_ catalisador_para_adesivo_plastico.pdf $>$ Acesso em: 26 fev. 2013.

COUTINHO, G. A. et al. Educação ambiental aplicada na indústria automobilística. In: CONGRESSO DE MEIO AMBIENTE DA AUGM, 6., 2009, São Carlos. Anais... São Carlos: UFSCar, 2009. v. 1.

COUTINHO, G. A. et al. Educação ambiental aplicada na indústria automobilística. Conhecimento Interativo, v. 5, n. 1, p. 55-68, jan./jun. 2011.

FARIAS, C. L. 5 R's - Reduce, Re-use, Recycle, Recover and Residual Management. Bela Vista, 2003. Disponível em: <http://www.keyassociados.com.br/imprensa-5rs. php>. Acesso em: 19 mar. 2008.

FREITAS, T. Setor automotivo é principal alvo da indústria química. Folha de São Paulo, São Paulo, 27 jan. 2013. Disponível em: <http://app.folha.com/m/noticia/203007>. Acesso em: 10 fev. 2013. 
INSTITUTO BRASILEIRO E ADMINISTRAÇÃO MUNICIPAL. Painel II - Resíduos Sólidos Industriais e Mecanismos de Desenvolvimento Limpo. In: SEMINÁRIO - PANORAMA DOS RESÍDUOS SÓLIDOS NO BRASIL, 2008, Rio de Janeiro. Anais eletrônicos... Rio de Janeiro: IBAM, 2008. Disponível: $<$ http://www.ibam.org.br/publique/media/rsi\%20 e\%20mdl.pdf>. Acesso em: 17 mar. 2009.

JACOB, A. Spray-up offers process improvements. Reinforced Plastics, v. 46, n. 1, p. 32-34, jan. 2002. http://dx.doi.org/10.1016/S0034-3617(02)80026-1

LIMA, G. Direto da prancheta ao usuário final. Revista do Plástico Reforçado, 2006. Disponível em: <http:// www.revistadoplasticoreforcado.com.br/automotivo/ sessao_auto.html>. Acesso em: 11 mar. 2010.

LAYRARGUES, P. P. O cinismos da reciclagem: o significado ideológico da reciclagem da lata de alumínio e suas implicações para a educação ambiental. In: LOUREIRO, C. F. B.; LAYRARGUES, P. P.; CASTRO, R. S. Educação ambiental: repensando o espaço da cidadania. 2. ed. São Paulo: Cortez, 2002. p. 179-219.

LOUREIRO, C. F. B. Educação Ambiental e movimentos sociais na construção da cidadania ecológica e planetária. In: LOUREIRO, C. F. B.; LAYRARGUES, P. P.; CASTRO, R. S. (Org.) Educação ambiental: repensando o espaço da cidadania. 2. ed. São Paulo: Cortez, 2002. p. 69-98.

MATHEUS, M. A. Fiberglass - Aprenda fibra de vidro. Ribeirão Preto, 2002. 132 p.

MEKOL LTDA. Ficha de Informação de Segurança de Produtos Químicos. Jandira, 2008. Disponível em: <http://www.mekol.com.br/FISPQCatalisador12.pdf> Acesso em: 26 fev. 2013.

MILAN, G. S.; GRAZZIOTIN, D. B. G. Implantação da Produção mais Limpa em uma empresa do setor plástico. In: ENCONTRO NACIONAL DE ENGENHARIA DE PRODUÇÃO, 28, 2008, Rio de Janeiro. Anais eletrônico... Rio de Janeiro: ABEPRO-ENEGEP, 2008. Disponível em: <http://www.abepro.org.br/enegep2008/ resumo_pdf/enegep/TN_STO_077_542_10609.pdf>. Acesso em: 22 jun. 2008.

PINTO, K. N. C. Reciclagem de resíduos de materiais compósitos de matriz polimérica: poliéster insaturado reforçado com fibras de vidro. 2002. Dissertação (Mestrado)-Universidade de São Paulo, São Paulo, 2002.

RIOS, M. Brasilplast 2003: um balcão de negócios. Revista Plástico Moderno on-line, n. 340, 2003. Disponível em: <http://www.plastico.com.br/revista/pm340/brasilplast1. htm>. Acesso em: 22 jul. 2010.

SPERANDIO, S. A.; GASPAR, M. A. Gestão socioambiental em empresas industriais: redução, reutilização e reciclagem dos resíduos gerados. In: SEMINÁRIO DE ADMINISTRAÇÃO: DESAFIOS DA GESTÃO: ECONÔMICO, SOCIAL E AMBIENTAL, 15., 2012. São Paulo. Anais eletrônico... São Paulo: FEA-USP, 2007. Disponível em: <http://www.ead.fea.usp.br/ semead/10semead/sistema/resultado/trabalhosPDF/258. pdf> Acesso em: 01 mar. 2013.

SILVA, C. Brasil garante posição entre maiores do mundo. O Estado de São Paulo, São Paulo, 23 ago. 2009. Disponível em: <http://www.estadao.com. br/estadaodehoje/20090823/not_imp423145,0.php>. Acesso em: 22 jul. 2010.

TOCCHETTO, M. R. L. Gerenciamento de Resíduos Sólidos Industriais. Santa Maria: UFSM, 2005. 95 p. Curso de Química Industrial.

VILHENA, A.; POLITI, E. Reduzindo, reutilizando, reciclando: a indústria ecoeficiente. São Paulo: CEMPRE/SENAI, 2005. 94 p.

WEG S.A.. Ficha de Informação de Segurança de Produtos Químicos. Jaraguá do Sul, 2012. Disponível em: <http://ecatalog.weg.net/files/wegnet/FISPQ/POR/ TL/10003071.pdf>. Acesso em: 26 fev. 2013. 